\title{
The Use of Rotation Flap to Cover a Facial Defect-A Case Study
}

\author{
Kwesi Okumanin Nsaful \\ Plastic, Reconstructive Surgery and Burns Unit, 37 Military Hospital, Accra, Ghana \\ Email:knsaful@yahoo.co.uk
}

How to cite this paper: Nsaful, K.O. (2020) The Use of Rotation Flap to Cover a Facial Defect-A Case Study. Modern Plastic Surgery, 10, 101-107.

https://doi.org/10.4236/mps.2020.104012

Received: May 8, 2020

Accepted: July 31, 2020

Published: August 3, 2020

Copyright (C) 2020 by author(s) and Scientific Research Publishing Inc. This work is licensed under the Creative Commons Attribution International License (CC BY 4.0).

http://creativecommons.org/licenses/by/4.0/

\begin{abstract}
Background: There are often situations that require the correction of facial defects. Local fasciocutaneous flaps provide a reasonable option for reconstruction of facial defects with good colour and texture match and good success rate. Among the various options of local flaps is the use of a rotation flap. Aim: The aim of this work is to demonstrate the reliability of the rotation flap in the correction of facial defects and its ability to achieve a good aesthetic outcome by applying the knowledge of facial aesthetic units. Case Presentation: This is a case report of a 28 -year-old woman who suffered an avulsion injury to the face with loss of facial tissue resulting in exposure of the left $\mathrm{zy}$ gomatic bone. The defect measured $5 \mathrm{~cm} \times 6 \mathrm{~cm}$. A rotation flap was used to cover the defect after the wound had been previously irrigated and debrided. Her wounds healed well. She suffered no facial nerve injury. The rotation flap resulted in a good colour match with no disruption of facial contour. Conclusion: The Rotation flap provides a reasonable option for reconstruction of facial defects with good colour and texture match.
\end{abstract}

\section{Keywords}

Facsiocutaneous Flaps, Rotation Flap, Avulsion Injury, Facial Contour

\section{Introduction}

The reconstructive surgeon is often confronted with situations that require the correction of facial defects. There is a wide range of options available to the reconstructive surgeon for repairing a given facial defect. These include traditional methods like healing by secondary intention and primary closure. Other options include the use of a skin graft, the use of local or regional flaps, as well as free tissue transfer [1] [2] [3] [4] [5].

Local fasciocutaneous flaps provide a reasonable option for reconstruction of 
facial defects with good colour and texture match and good success rate [6]. Thus, they often produce superior functional and aesthetic results. Among the various options of local flaps is the use of a rotation flap. A rotation flap is a semicircular skin flap that is rotated into the defect on a fulcrum point. Rotation flaps provide the ability to mobilize large areas of tissue with a wide vascular base for reconstruction [7].

Rotation flaps are particularly useful when the proposed donor site of the flap is the lateral aspect of the face. These flaps are advantageous because they have a particularly wide base and thus have an excellent blood supply. Their disadvantage is that they may require relatively extensive cutting beyond the defect to develop the flap, thus increasing the risk of nerve damage as well as bleeding [8] [9].

One of the important considerations in any type of facial surgery, especially in facial reconstructive surgery, is the use of the aesthetic subunits. Gonzales-Ulloa [10] first described the regional aesthetic units of the face (Figure 1) in an effort to emphasize the need for restoring facial skin units in complete regions as opposed to "patch" work. He believed that superior surgical results can be obtained in complex facial reconstruction by replacing lost skin with grafts or flaps of similar histology, thickness, and texture.

Placing local flap incisions along the borders of the aesthetic subunits of the

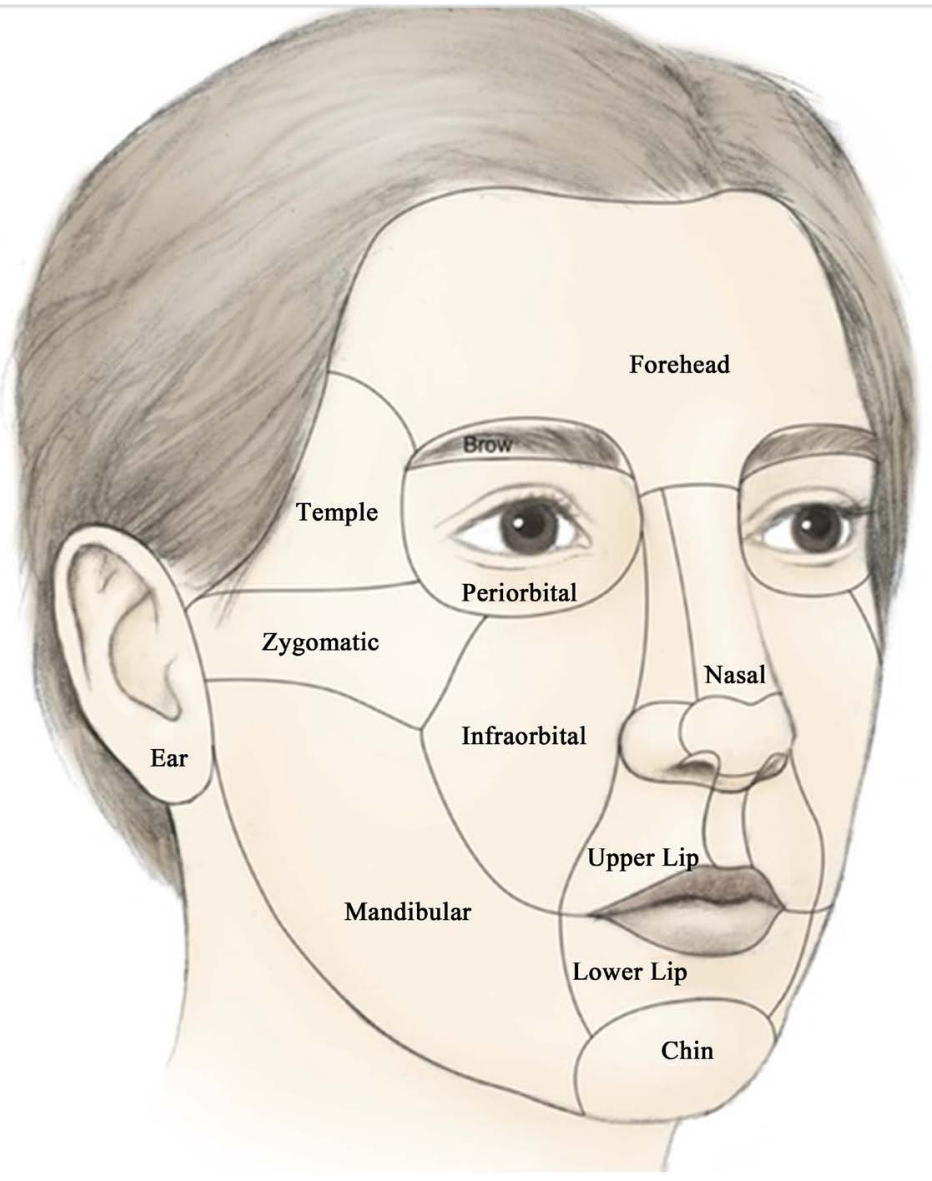

Figure 1. Aesthetic units of the face. 
face can help preserve the neighboring aesthetic subunit, prevent disruption of tissue contours and function and conceal incisions in natural shadows formed by these borders.

The aim of this work is to demonstrate the reliability of the rotation flap in the correction of facial defects and its ability to achieve a good aesthetic outcome by applying the knowledge of facial aesthetic units.

\section{Case Report}

This is a case report of a 28-year-old lady with a post-traumatic defect on the left side of her face. She was involved in a Road Traffic Accident and suffered an avulsion injury to the face with loss of facial tissue resulting in exposure of the left zygomatic bone. The defect measured $5 \mathrm{~cm} \times 6 \mathrm{~cm}$.

On the day of presentation, her wound was irrigated with minimal debridement under sedation. She was admitted to the Plastics and Reconstructive Surgery ward and had second -look wound irrigation on day 3. Subsequently, she was prepared for a flap cover.

The Surgery was performed under general anaesthesia. Markings for a rotation flap were made. The flap was placed inferior to the defect (Figure 2). The site was infiltrated with $0.5 \%$ lidocaine with adrenaline. The flap was raised as a fasciocutaneous flap. Effort was made not to injure the facial nerve. Haemostasis was secured with the use of diathermy. The flap was secured in place by suturing in layers with Vicryl 4/0 subcuticular stitches to skin (Figure 3). Intra-operatively, prophylactic antibiotic was administered (1 gm st. Ceftazidime).

Post-operatively the patient rested with her head at a 45 -degree angle. She was put on $1 \mathrm{gm}$ Ceftazidime bd for 48 hours and then Oral Amoksiclav $1 \mathrm{gm}$ bd for 5 days with Clindamycin Oral $300 \mathrm{mg}$ tds for 5 days. She was also put on analgesics.

The post-operative period was uneventful. Her wounds healed well. She suffered no facial nerve injury. This option resulted in a good colour match with no disruption of facial contour (Figure 4).

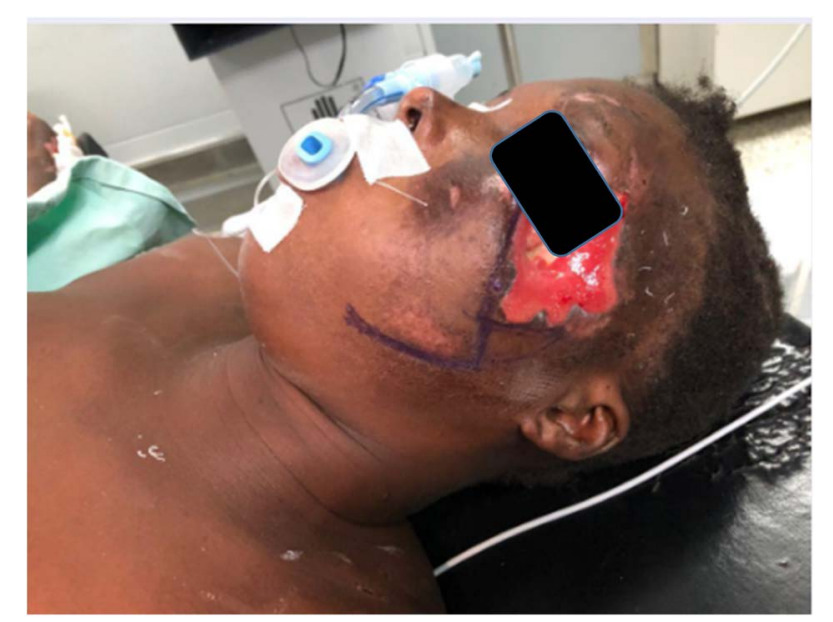

Figure 2. Facial defect with zygomatic bone exposed. Pre-operative Rotational flap markings made. 


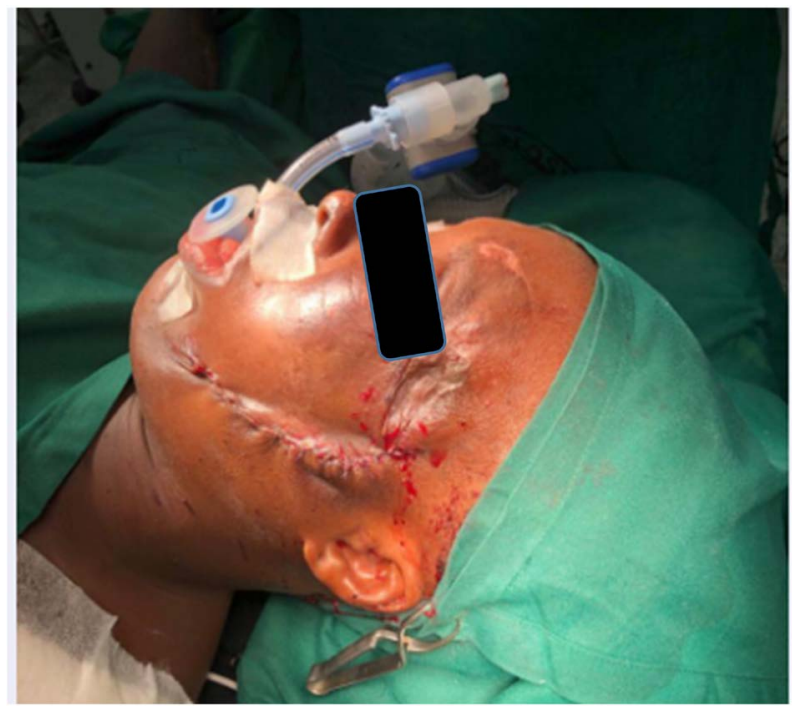

Figure 3. Flap rotated into place and secured.

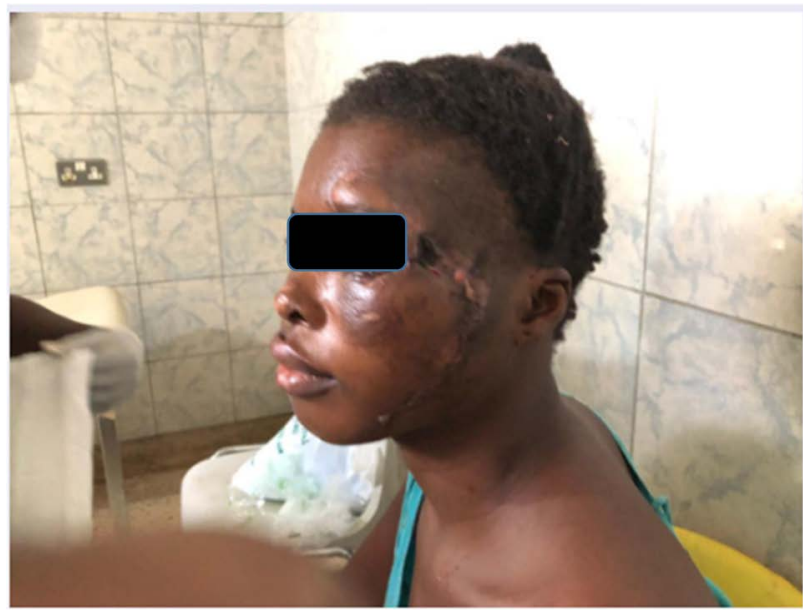

Figure 4. Patient post-operative day 10.

\section{Discussion}

A facial injury can be one of the most challenging problems presented to the reconstructive surgeon. Trauma can lead to complex facial injuries with missing tissue. Motor vehicle collisions make up the majority of these injuries followed by bite wounds and ballistic injuries [11].

Patients with facial injury may have their lives and self-esteem compromised temporarily or permanently [12]. The ultimate objective of treatment is to achieve functional and cosmetic restoration. Local flaps in the armamentarium of the reconstructive surgeon when aptly applied well serves this purpose.

A local flap comprises the skin and subcutaneous tissue with a direct vascular supply, which is transferred to an adjacent or nearby site. Local flaps have several advantages such as reliable blood supply, good skin texture, and colour match. Additionally, most provide a single-stage procedure

An argument against primary use of local flaps is that this flap is eliminated as 
a possibility for further reconstruction if the primary repair is unsuccessful. Thus, the employment of a local flap requires good planning and execution. Excessive tension or wound contracture can result in distortion of surrounding tissue.

Options available to the Reconstructive Surgeon for facial reconstruction include the bilobed flap, glabella V-Y advancement flap, and Limbergflap. However, these can only be used if the area of the defect is less than $15 \mathrm{~mm}$ [13]. Another frequently deployed local flap for facial reconstruction- mainly for the medial and lateral canthal, or nasal defects- is the forehead flap. However, the disadvantage of this flap is that the scar of the donor site remains on the forehead of the patient.

Rotation flaps that do not properly disperse tension vectors can distort sensitive structures such as the mouth and eyelid. The flap has to be properly sized to sit perfectly into the defect without tension. Determining the type of local flap to use depends on the location of the defect and the flap donor site. When planning placement and design of a local flap, there are important tenets of reconstruction to bear in mind [14].

1) Incisions and closures should be along relaxed skin tension lines (RSTLs).

2) Closures should be tension free. This is best accomplished by undermining the skin along the lines of maximal extensibility (LME). LME is the direction in which skin is most extensible and runs perpendicular to RSTLs.

3) Flaps should respect and preserve facial aesthetic and functional subunits.

The cheek rotation flap is a reliable and trustworthy surgical procedure, and is applicable in the case of the large defect area including medial and lateral can thus and nasal sidewall. The medial canthal defects can be reconstructed successfully by the cheek rotation flap, which transfers the components of the lateral lower eyelid (intact conjunctiva, tarsus, and skin) and fix those to the medial canthus. When it comes to the lateral canthal defects, it is performed by using high arch-shaped design and cheek mucus membrane grafts. For large nasal sidewall defects, necrosis is rare and the flap has good survival as a result of sufficient blood flow of facial arteries [13].

The Cheek rotation flap has been used to reconstruct medial and lateral canthi defects, and furthermore, the large defects of the nasal sidewall can be reconstructed satisfactorily. Therefore, if a large defect of the nasal sidewall needs to be reconstructed, the cheek rotation flap may be considered as a flap of choice to replace the paramedian forehead flap. The scar from the cheek rotation flap can be hidden inside of the RSTL,

Flap necrosis results from ischemia of the distal end of the flap as a result of impaired blood flow. Blood flow within a flap can be compromised by; making the pedicle too small to support the flap, making the flap too thin which disrupts the dermal plexus, or by excessive undermining which disrupts perforating vessels feeding the pedicle. Flap necrosis can also occur if the closure is done under tension.

Facial nerve injury is always a possible complication of facial surgery and fa- 
cial paralysis can be a devastating consequence. An effort was made to raise a Facsiocutaneous flap in so doing avoiding injury to the facial nerve. Thus raising local flaps of the face can be safely done.

\section{Conclusion}

The Rotation flap provides a reasonable option for reconstruction of facial defects with good colour and texture match. With proper planning and execution, rotation flaps are a versatile technique that can be used to produce excellent functional and cosmetic outcomes in the reconstruction of facial defects.

\section{Patient Consent}

The patient provided written consent for the use of her images.

\section{Conflicts of Interest}

The author declares no conflicts of interest regarding the publication of this paper.

\section{References}

[1] Summers, B.K. and Siegle, R.J. (1993) Facial Cutaneous Reconstructive Surgery: General Aesthetic Principles. Journal of the American Academy of Dermatology, 29, 669-681. https://doi.org/10.1016/0190-9622(93)70230-Q

[2] Baker, S.R. (1994) Local Cutaneous Flaps. Otolaryngologic Clinics of North America, 27, 139.

[3] Baker, S.R. (1990) Regional Flaps in Facial Reconstruction. Otolaryngologic Clinics of North America, 23, 925.

[4] Ducic, Y. and Herford, A.S. (2001) The Use of Palatal Island Flaps as an Adjunct to Microvascular Free Tissue Transfer for Reconstruction of Complex Oromandibular Defects. Laryngoscope, 111, 1666. https://doi.org/10.1097/00005537-200109000-00033

[5] Herford, A.S. and Zide, M.F. (2001) Reconstruction of Superficial Skin Cancer Defects of the Nose. Journal of Oral and Maxillofacial Surgery, 59, 760-767. https://doi.org/10.1053/joms.2001.24290

[6] Jagdeep, K.R., Kaustubh, S. and Shende, J. (2016) Overview of Local Flaps of the Face for Reconstruction of Cutaneous Malignancies: Single Institutional Experience of Seventy Cases. Journal of Cutaneous and Aesthetic Surgery, 9, 220-225. https://doi.org/10.4103/0974-2077.197029

[7] Baker, S.R., Ed. (2014) Local Flaps in Facial Reconstruction. 3rd Ed., Elsevier Saunders, Philadelphia.

[8] Liu, F.Y., Xu, Z.F., Li, P., Sun, C.F., Li, R.W., Ge, S.F., et al. (2011) The Versatile Application of Cervicofacial and Cervicothoracic Rotation Flaps in Head and Neck Surgery. World Journal of Surgical Oncology, 9, Article Number: 135. https://doi.org/10.1186/1477-7819-9-135

[9] Boyette, J.R. and Vural, E. (2011) Cervicofacial Advancement-Rotation Flap in Midface Reconstruction: Forward or Reverse. Otolaryngology-Head and Neck Surgery, 144, 196-200. https://doi.org/10.1177/0194599810391391

[10] Gonzales-Ulloa, M. (1956) Restoration of the Face Covering by Means of Selected 
Skin in Regional Aesthetic Units. British Journal of Plastic Surgery, 9, 212-221. https://doi.org/10.1016/S0007-1226(56)80036-2

[11] Herford, A.S. (2004) Early Repair of Avulsive Facial Wounds Secondary to Trauma Using Interpolation Flaps. Journal of Oral and Maxillofacial Surgery, 62, 959-965. https://doi.org/10.1016/j.joms.2004.01.020

[12] Hochberg, J., Ardenghy, M., Toledo, S., Ardenghy, M.E., Miura, Y. and Schiebel, F. (2001) Soft Tissue Injuries to Face and Neck: Early Assessment and Repair. World Journal of Surgery, 25, 1023-1027. https://doi.org/10.1007/s00268-001-0054-Z

[13] Kyung, P.K., Ho, S.S., Jun, H.C., Sam, Y.L., Do, H.L., Seong, H.K., Hong, M.K., Jae, H.H. and Kwang, S.K. (2016) The Versatility of Cheek Rotation Flaps. Archives of Craniofacial Surgery, 17, 190-197. https://doi.org/10.7181/acfs.2016.17.4.190

[14] Shiayin, Y., Carl, T. and Jeffrey, M. (2019) Local Flaps for Facial Reconstruction. Open Access Atlas of Otolaryngology, Head \& Neck Operative Surgery. 